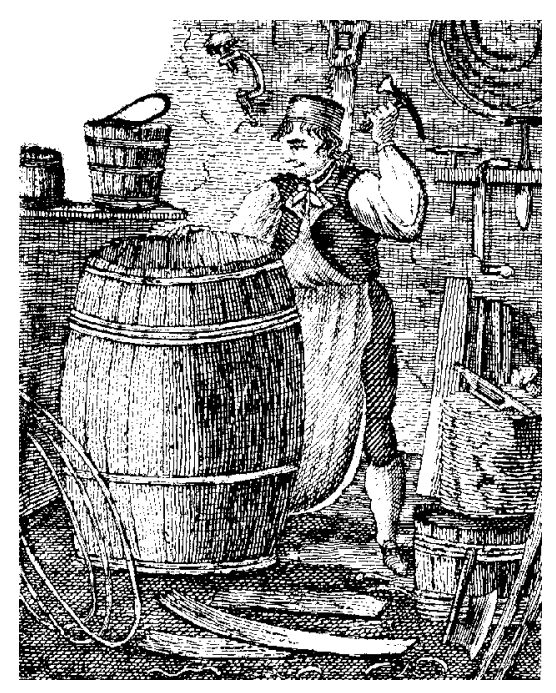

\title{
LA DIVERSIDAD ÉTNICA Y CULTURAL DE COLOMBIA: UN DESAFÍO PARA LA EDUCACIÓN
}

\author{
Silvio Aristizábal Giraldo \\ Profesor Universidad Pedagógica Nacional
}

\section{DIVERSIDADÉTNICA Y CULTURAL}

La mayoría de los colombianos cuando escucha hablar de la diversidad étnica y cultural de la nación piensa que esta expresión se refiere sólo a la existencia de indígenas y afrocolombianos. Pocos entienden que la expresión alude en algún sentido a las diferencias entre un costeño, un valluno y un llanero. Muchos consideran que entre los indígenas no hay diferencias y para otros, los raizales de San
Andrés y Providencia no se distinguen de los chocoanos. Sin embargo, la realidad es bien diferente. Veamos un poco cómo es la situación:

\subsection{Pueblos Indígenas}

Existen en el país más de 80 Pueblos Indígenas que hablan 66 lenguas. Cada uno de estos pueblos tiene su cosmovisión, sus códigos diferentes de significación de la realidad, sus valores, creencias, costumbres y expresiones artísticas y religiosas que los diferencian entre sí y con los demás colombianos.

Según el Departamento Nacional de Estadística (DANE) la población indígena en Colombia para 1997, se calculaba en 701.860 personas, lo que equivale al $1.75 \%$ de la población total del país (Arango y Sánchez, 1998: 19). No obstante su reducida proporción en comparación con el total de la población, Colombia ocupa, después de Brasil, el segundo lugar en América Latina en cuanto a número de pueblos 
indígenas. De éstos, sólo dos pueblos sobrepasan las 100.000 personas: los nasa, más conocidos como paeces (118.845) y los wayúu (144.003). Además, hay varios grupos con menos de 100 personas, por lo cual se les considera en inminente peligro de extinción, entre ellos están los taiwano (19), los pisamira (54), los makaguaje (50) y los bara (96) (Arango y Sánchez, 1998).

Quizás donde más se puede apreciar la diversidad indígena es en la lengua. Según la investigadora María Trillos, la diversidad lingüística de los indígenas colombianos es tal vez única en América. Las 66 lenguas inventariadas actualmente pertenecen a 18 familias lingüísticas diferentes. Se encuentran lenguas representantes de las grandes familias lingüísticas suramericanas: Arawak, Caribe, Quechua, Chibcha, Tupí-Guaraní. Hay lenguas pertenecientes a familias regionales como Tukano, Guahibo, Uitoto, y lenguas aisladas como el Páez, el Guambiano, el Kamëntsá o el Ticuna (Trillos, 1998b).

Hay lenguas tonales como las del suroriente asiático o de Africa Central; flexionantes a la manera del griego o el latín (kogui, damana, ika), aislantes como las lenguas malayo-polinesias (emberá); polisintéticas a la manera del esquimal (kamëntsá); acusativas como el español o el inglés; ergativas a la manera del vasco o las lenguas del Cáucaso; mixtas como algunas lenguas australianas o el maya (damana, arhuaco) (Trillos, 1998b).

Otro aspecto que muestra la diversidad de las culturas indíge-

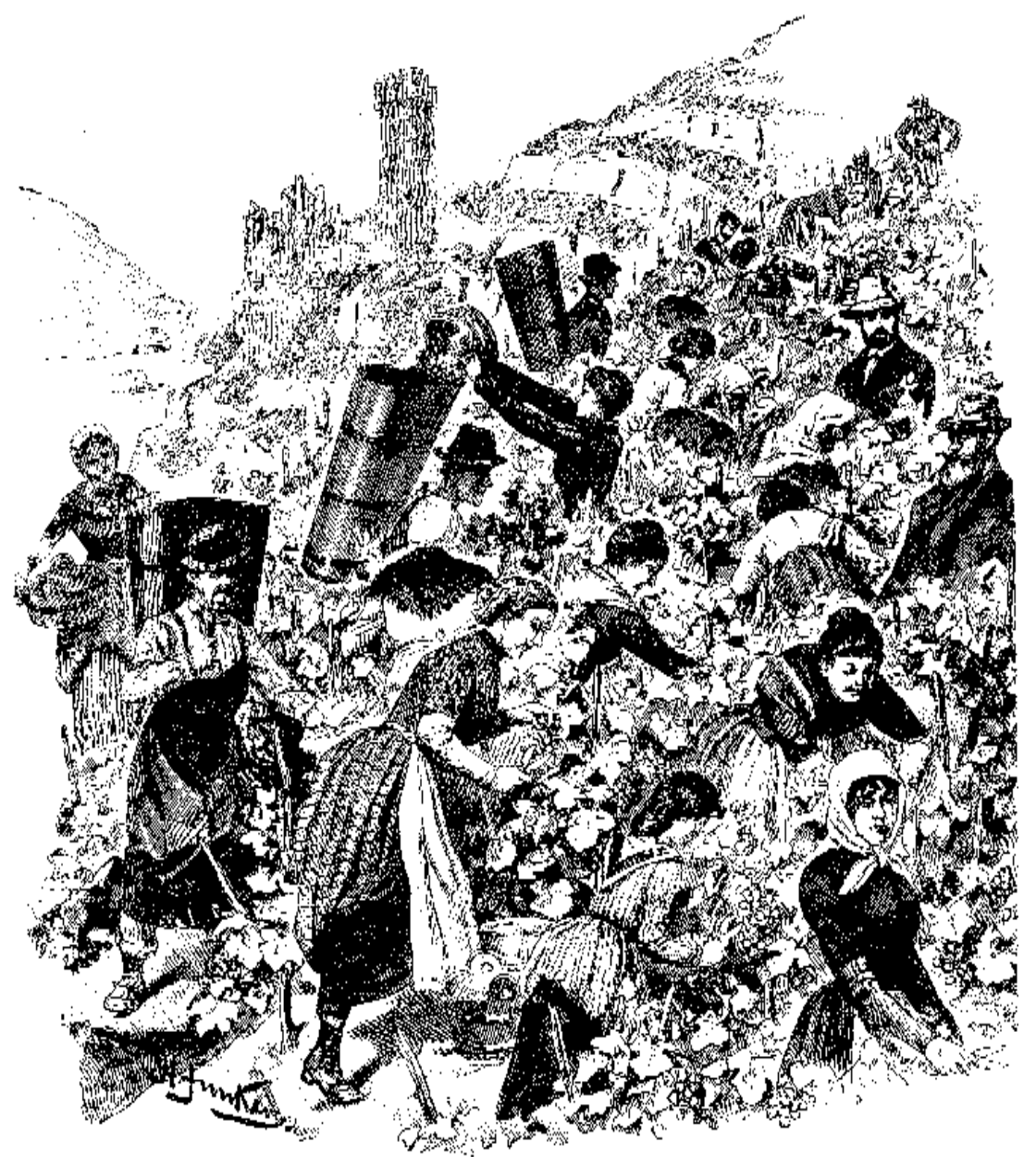

nas es el referido a las relaciones de dichos pueblos con la naturaleza, resultado de miles de años de experiencia y de convivencia con ecosistemas determinados. Estas concepciones se expresan a través de los mitos, los ritos y la variedad de prácticas productivas.

\subsection{Afrocolombianos}

Los afrocolombianos se calculan entre cinco y ocho millones de personas (Escobar y Pedrosa, 1996: 247). Están asentados a lo largo de la Costa del Pacífico, desde Panamá hasta el Ecuador; en la Costa Atlántica; en las tierras bajas de los valles interan- dinos de los ríos Magdalena, Cauca y Patía y en las principales ciudades. Los habitantes de San Basilio de Palenque hablan, además del español, una lengua que tiene muchas expresiones del portugués y del español, y en la cual sus palabras africanas y su sustrato gramatical provienen del ki-congo, una lengua bantú (Arocha, 1999 y Friedemann y Arocha, 1986).

Los esclavos importados a América, procedían de grupos con una gran diversidad étnica y linguística. Muchos de ellos provenían de grandes civilizaciones de los reinos de África Central y de los imperios sudaneses de 
Ghana, Malí y Songay, "Estados legendarios que ostentaron épocas de poder y esplendor comparables a las de las civilizaciones que por el mismo tiempo surgían en Europa: reyes y cortes; sociedades y jerarquías religiosas; mercados y ejércitos; sacerdotes y artistas; arquitectos y artesanos; mineros y orfebres; bibliotecas y maestros" (Friedemann y Arocha, 1986: 18).

Arrancados de su hábitat y transportados en condiciones infrahumanas a otro continente donde se les sometía a la más abyecta esclavitud con individuos de otros pueblos de lengua y cultura diferente, los afroamericanos se vieron en la necesidad de desarrollar procesos de reintegración étnica y construcción de nuevas identidades enraizadas en sus culturas originarias, pero tomando elementos de las culturas europea y americana. En este proceso la memoria representó el mayor patrimonio de los capturados, pues gracias a ella pudieron reconstruir sus identidades (Arocha, 1999). Durante el período de la esclavitud no llegaban, según Arocha, "poblaciones aglutinadas sino cargas de personas distintas" (Arocha, 1999: 38, enfatizado en el original). Por eso, afirma el citado autor:

"Pensemos que aquí pudo haber desembarcado un arquitecto, pero no la arquitectura dogón de Malí; un sacerdote, pero no todo un complejo ceremonial, mítico y litúrgico de los ngolas; un médico, pero no la medicina balanta del río Cacheo. Una mayoría de postadolescentes, cuya formación por lo general estaba lejos de concluir, se bajó de las naves con recuerdos que aplicó a las riquezas del nuevo continente y a las artes de indios y españoles, hasta ir haciendo culturas nuevas. Éstas ostentaban el legado africano, pero no eran africanas; dejaban ver los préstamos de América y Europa, pero no eran ni americanas ni europeas" (Ibíd.).

\subsection{Raizales}

Son unos 30.000, habitan en San Andrés, Providencia y Santa Catalina; además del creolle, hablan el inglés como segunda lengua ${ }^{1}$. Los raizales han logrado, mediante la Ley 70 de 1993, el reconocimiento como pueblo diferente de los afrocolombianos, ya que son el resultado de un complejo proceso de interacción entre africanos importados como esclavos, africanos llegados de las islas del Caribe e ingleses y europeos, que los habían traído para sus plantaciones de algodón y sus actividades comerciales. El archipiélago estaba bajo el dominio de la Corona española, sin embargo, predominaron la lengua inglesa y la religión bautista. En el siglo XX el Estado colombiano hizo numeroso intentos por castellanizarlos y convertirlos al catolicismo, pero ellos han resistido manteniendo su identidad.

\section{La negación de lo afro}

Si las culturas indígenas en Colombia han sido discriminadas, la situación para las culturas afrocolombianas y para los raizales ha sido aún más grave. Sus aportes a la formación de la na-

\footnotetext{
${ }^{1}$ La población raizal en San Andrés es minoritaria debido a la inmigración de continentales (costeños, paisas, siriolibaneses).
}

cionalidad han sido sistemáticamente desconocidos. Han sido vistos como piezas de engranaje económico y colonial, supeditadas a la racionalidad económica de los amos. "... la gente negra ha sido mirada esencialmente como esclava, es decir, en tanto que individuos despersonalizados y desocializados por los mecanismos de la trata atlántica... Como objetos o mercancías, cuyo único nexo con la sociedad colonial fue el amo" (Maya, 1994: 142).

Al ser considerados como mercancía, a los negros se les negó su historia, su nexo con su pasado africano. "Al ser considerada gente sin pasado, se le clasificó como incapaz de memorizar su devenir y, por consiguiente, de ser protagonistas de su propia historia en suelo americano; incapaces también de adaptarse y transformar la sociedad colonial y republicana" (Ibíd.).

\section{Según Bastide (1963),}

"En el interior del universo simbólico afroamericano parecen surgir dos modos fundamentales de organización, según la relación con Africa, su continente de origen: 'la africanidad manifiesta' (los grandes sistemas mágico-religiosos afro-cubanos, afro-haitianos y afro-brasileños), que guarda trozos enteros de la mitología, los ritos e incluso las lenguas de las culturas africanas de origen y a menudo reivindica los lazos de pertenencia con ellas; y la 'africanidad latente', (los sistemas de pensamiento afro-panameño, afro-venezolano, afrocolombiano, afro-ecuatoriano y afro-peruano), que conserva varios ítem menores de origen afri- 
cano, pero que los ha integrado -así como otros de origen europeo e indio-, en una lógica de conjunto recreada y original, y además ha perdido conciencia de su origen africano" (citado por Losonczy, 1993: 45).

Frente a esta tesis, la historiadora Adriana Maya (1996), plantea que si bien la africanía en Colombia ha tenido características diferentes a las observadas en Brasil y el Caribe, aún es posible encontrar "huellas de africanía" -utilizando una expresión de Nina de Friedemann²- porque su memoria permaneció viva y les permitió la reconstrucción étnica, social y política ${ }^{3}$. Maya argumenta que la carencia de registros etnográficos e históricos sobre "candomblé", "santería" o "vudú" en nuestro país, así como "la ausencia contemporánea de estas manifestaciones explícitas de africanidad" no son argumentos "para descartar la permanencia de lo sagrado africano en Colombia, ni (para negar) la importancia que durante la colonia neogranadina tuvieron estos legados espirituales en la sobrevivencia demográfica y cultural de la diáspora africana en nuestro medio" (Maya, 1996: 29). En otro de sus escritos anota la autora que si bien la esclavitud astilló y fragmentó la memoria corporal de los africanos y sus descendientes, no logró aniquilar ni suprimir los legados africanos (Maya, 1998b).

\footnotetext{
${ }^{2}$ Según Friedemann "huellas de africanía" son "memorias, sentimientos, aromas, formas estéticas, texturas, colores, armonía, es decir, materia prima para la etnogénesis de la cultura negra" (en Maya 1996: 30).

${ }^{3}$ Diversos trabajos investigativos de Maya apoyan su tesis. Ver bibliografía, al final.
}

Arocha sostiene una tesis similar a la de Maya, cuando afirma: "pese a la especificidad de la africanía en Colombia, negar sus memorias equivale a impugnar la humanidad de los esclavizados y sus descendientes. El hecho de que a ellos se les hubiera privado de la libertad no significó que los amos les hubieran amputado la capacidad de recordar y, menos aún, de llevar a cabo procesos de reconstrucción política, social y cultural" (Arocha, 1999: 27).

No obstante la invisibilidad a que fueron condenados los afrocolombianos, su resistencia a la esclavitud y a la aniquilación siempre se mantuvo. Al respecto afirma Maya que las creencias y prácticas de los esclavos africanos durante la Colonia, calificadas por los españoles como actos de "brujería" guiados por el demonio, en realidad eran manifestaciones de la espiritualidad originaria de Africa, mediante las cuales aquellos expresaban su humanidad (Maya, 1992 y 1996). Esta resistencia ancestral se ha fortalecido con los diferentes movimientos afrocolombianos, que en las últimas décadas han mostrado una gran vitalidad.

\subsection{Rom o Gitanos}

En el mundo los gitanos pertenecen a tres pueblos diferentes: Cíngaros-Kalderash, Manuches y Gitanos. Su lengua es el romanó o romanés, el cual, no obstante sus variantes dialectales, les permite la comunicación en todo el mundo. Su llegada a América, parece haberse dado simultáneamente con el arribo de los primeros españoles. Las mi- graciones iniciales tuvieron un carácter disciplinario, ya que muchos gitanos que no aceptaban la orden de expulsión de Europa, eran enviados a América. En siglos posteriores hubo una emigración voluntaria. Años más tarde se desató la persecución contra ellos y la Legislación Indiana ordenó la deportación inmediata de aquellos que se encontraran en América.

Hacia mediados del siglo XIX hubo nuevas migraciones a Colombia, a través de Panamá. Después de la Segunda guerra mundial se presentó un aumento de la población gitana en nuestro país, la cual es estimada por algunos, actualmente, en 8.000 y por otros en 10.000 personas, pertenecientes al grupo CíngaroKalderash. Hay diferentes linajes o clanes como los Bolochoc, Boyhás, Churon, Mijhais, Jhanés,, Langosesti y Bimbay, aunque muchos de ellos han adoptado apellidos como Gómez o Mendoza. Sus principales asentamientos en Colombia están en Itagüí (Antioquia), Bucaramanga y Bogotá (Colombia, DNP, 1999).

Entre los elementos constitutivos de la identidad del pueblo rom se señalan: idioma propio; larga tradición nómada y su transformación en nuevas formas de itinerancia; valoración de los grupos de edad y sexo como ordenadores de estatus; cohesión interna y diferenciación frente al no rom; organización social basada en los grupos de parentesco; derecho consuetudinario, conocido como la "ley gitana" o Kriss, expresada en un conjunto de normas tradicionales e instituciones que regulan su aplicación (lbíd.). 
El Ministerio del Interior, a través de conceptos emitidos por la Dirección de Asuntos Indígenas y la Dirección de Comunidades Negras y Otras Colectividades Étnicas, reconoció a los gitanos su carácter de grupo étnico ${ }^{4}$. Igualmente, el Plan de Desarrollo 1998-2002, "Cambio para construir la Paz", consagró el siguiente aparte al pueblo rom: "El Gobierno Nacional en cabeza del Ministerio del Interior, velará por la integración de estas comunidades a sus propósitos de lucha contra la pobreza y mejoramiento de su calidad de vida, respetando sus particularidades culturales y concertando con este grupo las acciones para la atención de sus principales problemas".

Indígenas, afrocolombianos, raizales y rom reclaman el derecho a la diversidad como pueblo, es decir, exigen el reconocimiento de su identidad étnica. La identidad étnica o etnicidad se entiende como el sentido de pertenencia a un grupo, a partir de la aceptación de un origen común, una historia, una cultura, una lengua y unos valores comunes. Esta identidad se asume como opuesta a la identidad mayoritaria, la cual estaría asociada con grupos dominantes, a los cuales no se les aplicaría la noción de etnia. Los grupos étnicos, además del reconocimiento cultural y la identidad de grupo, reclaman derechos político-administrativos (Picó, 1999; Othón, 1992).

\footnotetext{
${ }^{4}$ Conceptos 0864 de la Dirección de Asuntos Indígenas y 2025 del 17 de diciembre de 1998, de la Dirección de Comunidades Negras y otras Colectividades Étnicas.
}

\subsection{La población "blanca" o Mestiza}

Además de los indígenas, afrocolombianos y rom que se reconocen a sí mismos como pueblos o etnias diferentes entre sí y con los demás colombianos, hay en el país más de 30 millones de habitantes, comúnmente llamados "blancos", que conforman la población mayoritaria y son el resultado de los procesos de mestizaje ocurridos en los últimos quinientos años.

Esta población, aunque relativamente homogénea, no reclama identidad como grupo étnico, tiene como lengua común el español, aunque con variantes dialectales, y es portadora de un sinnúmero de expresiones culturales diferentes. Incluye, entre otros, a paisas, vallunos, costeños, santandereanos, opitas, llaneros, nariñenses, boyacenses. Estas denominaciones hacen referencia no sólo a la geografía y a los ecosistemas sino también a diferencias en la historia ${ }^{5}$, la economía, el habla (dialectos regionales), la música, la tradición oral, la culinaria, la estructura familiar 6 , las fiestas, las

\footnotetext{
${ }^{5}$ Desde la década del cincuenta del siglo pasado se realizaron en el país numerosos estudios regionales sobre Antioquia, Cundinamarca, Cauca, Santander, la Costa Atlántica, la mayoría de los cuales tenía un fuerte énfasis en lo histórico, pero señalaban con mucha claridad la existencia de culturas regionales.

${ }^{6}$ A mediados del siglo pasado, la antropóloga Virginia Gutiérrez de Pineda realizó un estudio sobre la familia colombiana, para lo cual dividió el país en cinco macrorregiones culturales. Como resultado de dicho estudio publicó, en 1968, un libro titulado Familia y Cultura en Colombia, en el cual señala las diferencias existentes en los modelos de familia encontrados en esas
}

expresiones artísticas, las concepciones de la salud y la enfermedad y los estilos de conocimiento ${ }^{7}$.

\subsection{Otros inmigrantes}

Además de los pueblos indígenas, afrocolombianos, raizales,

macrorregiones. El libro presenta las características de la familia en cada uno de los "complejos culturales" establecidos por la autora: el complejo cultural antioqueño que comprende Antioquia, el viejo Caldas, parte del Tolima y el Valle del Cauca; el complejo cultural americano en el cual engloba departamentos como Nariño y el altiplano cundiboyacense; el complejo cultural hispánico donde incluye a los santanderes; el complejo cultural del litoral donde incluye a la costa Pacífica y Atlántica y las tierras bajas del Magdalena y Cauca. Además señala algunas características de la familia indígena, pero sin profundizar en el tema. No obstante haber sido escrito hace casi medio siglo, el libro constituye un aporte de gran significación para el conocimiento de la diversidad cultural del país y sigue siendo de obligatoria consulta para quienes se interesen por conocer las características culturales de las diferentes regiones de Colombia.

En lo referente a la diversidad musical sobresalen los trabajos investigativos del maestro Guillermo Abadía Morales, quien en su obra "Compendio General de Folklore Colombiano" (1977), analiza, además de la música, el folklore literario, coreográfico y demosófico (saberes populares) de las diferentes regiones del país.

${ }^{7}$ Un grupo de investigadores de la Universidad Pedagógica Nacional adelanta desde hace varios años un estudio sobre los modos de conocer en nuestro país. El grupo ha dividido a Colombia en varias regiones y a partir de la aplicación de una serie de cuestionarios ha demostrado la existencia de diferentes formas de conocimiento. En el libro más reciente sobre el tema, los autores señalan que desde el inicio de su trabajo, hace siete años han tenido una idea directriz según la cual, "la enorme diversidad que caracteriza a un país como Colombia supone también una diversidad en el plano de lo cognitivo" (Hederich M. y Camargo U., 1999: 12). Y en unos párrafos más adelante afirman: “...creemos haber logrado con éxito nuestro propósito fundamental de documentar empíricamente la existencia de una diversidad cognitiva 
rom y de los blancos o mestizos, existen en Colombia algunos núcleos de inmigrantes de otros países ubicados en distintas regiones del país. En la costa Atlántica, especialmente ha habido presencia de árabes, muchos de los cuales se han mezclado con los habitantes de la región. En Bogotá y en otras ciudades hay judíos, libaneses, japoneses y gentes llegadas de diferentes naciones europeas y americanas, y para la mayoría de los colombianos se va haciendo familiar la presencia de restaurantes chinos no sólo en las grandes ciudades, sino también en ciudades intermedias.

\subsection{Otras identidades}

La diversidad no se agota en lo étnico y lo cultural. Los jóvenes, las mujeres, los adultos mayores, los homosexuales, reclaman su derecho a la diferencia. Según Kymlicka y Norman, en estos casos, "el reclamo de los derechos grupales toma la forma de una demanda de representación especial en los procesos de decisión política del conjunto de la sociedad" (1997: 28). Esto diferencia sus reclamos de los de los grupos étnicos a quienes, de acuerdo con los citados autores, lo que les interesa "no es una mejor representación en el gobierno central sino más bien la transferencia del poder y de la jurisdicción legislativa, desde el

entre la población colombiana" (Ibíd.). Al señalar las consecuencias de este hecho, añaden los autores: "En este sentido, hemos propuesto que la diversidad cognitiva implica la diversidad de entornos, contenidos, enfoques y estrategias para la construcción de conocimiento, para el aprendizaje y para la enseñanza" (Ibíd.: 13). gobierno central hacia sus propias comunidades" (Ibíd.).

\section{EL RECONOCIMIENTO DE LA DIVERSIDAD}

Todos los colombianos, unos más que otros, hemos tenido la experiencia de encontrarnos con la diversidad étnica y cultural: Hemos visto los carnavales de Barranquilla, pero también los carnavales de negros y blancos de Pasto; bailamos vallenato, sabemos que el joropo es de los llanos y la guabina de la región andina ¿Quién no recuerda, al igual que Aureliano Buendía en Cien Años de Soledad, la llegada de los gitanos a su pueblo, con sus carpas, sus caballos, sus artículos de cobre y su promesa de adivinar la buenaventura? Por las calles de nuestros pueblos y ciudades hemos visto alguna vez indígenas y afrocolombianos, mestizos y blancos, europeos y asiáticos. Incluso, sin necesidad de salir de nuestra casa, la televisión nos trae la imagen y la voz de personas de otras culturas, no sólo del país sino del mundo.

A pesar de que la diversidad es un hecho cotidiano, los colombianos no logramos asimilarla: seguimos mirando a los otros como extraños, a veces, como enemigos; pero, sobre todo, seguimos pensando que los únicos valores son los de los "blancos" o mestizos. En Colombia ha dominado una cultura "societaria blanca, castellano-parlante y católica" (Monsalve, 1997: 1). Sobre esa matriz se ha construido la comunidad política colombiana. "Ello ha implicado una ideología del "blanqueamiento" como mecanismo para insertarse en esta sociedad, desde los tiempos de la colonia. Una expresión y resultado de este fenómeno es la apología del "mestizaje", que supone, en el campo del imaginario colombiano una identidad resultado de la síntesis de las razas, una nueva raza "cósmica", en la que se borran todas las diferencias étnicas y culturales" (Ibíd.).

La tesis del mestizaje, síntesis de las razas, contribuyó a hacer invisibles a los negros a los indígenas, a los gitanos y a los campesinos, y sirvió de máscara para ocultar la ideología de la superioridad blanca. De esta manera se estimuló el blanqueamiento genético y cultural, orientado a "borrar todas las diferencias para asimilar los valores de la cultura blanca: el igual derecho individual a la propiedad privada, la igualdad ante la ley respecto al sistema jurídico vigente, las formas de gobierno y elección, el derecho a la educación en el lenguaje dominante" (lbíd.).

En el plano jurídico fue necesario esperar hasta 1991 para que la diversidad se reconociera en nuestra Nación. El artículo $7^{\circ}$ de la Constitución Política declara: "El Estado reconoce y protege la

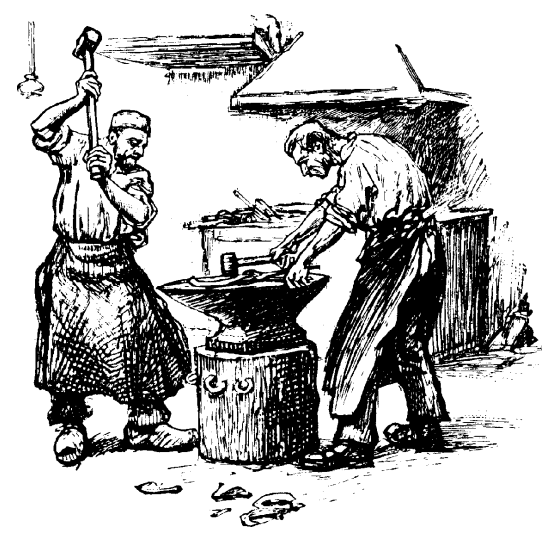


diversidad étnica y cultural de la Nación colombiana". Este principio, "lejos de ser una declaración puramente retórica, es el principio fundamental de diversidad étnica y cultural que proyecta en el plano jurídico el carácter democrático, participativo y pluralista de nuestra República" (Cifuentes, E., Corte Constitucional, 1993, en Ministerio de Cultura, 1998: 7$)^{8}$.

\section{LA EDUCACIÓN DE CARA A LA DIVERSIDAD}

La conformación del Estado colombiano en el siglo XIX siguió el modelo de los estados europeos en los cuales, unidad equivalía a uniformidad: una cultura, una lengua, una religión, unas cos-

\footnotetext{
${ }^{8}$ La nueva Carta Política, contiene numerosos artículos que reiteran y desarrollan el principio de la diversidad. Basta señalar algunos de ellos: la obligación del Estado y de las personas de proteger las riquezas culturales y naturales de la Nación (art. 8); el reconocimiento de las lenguas y dialectos de los grupos étnicos como oficiales en sus territorios y la obligación de la enseñanza bilingüe en las comunidades con tradición lingüística (art. 10); la declaración de las tierras comunales de los grupos étnicos y las tierras de resguardo como inalienables, imprescriptibles e inembargables (art. 63ㅇ); el derecho de los integrantes de los grupos étnicos de tener una formación que respete y desarrolle su identidad cultural (art. $68^{\circ}$, inc $5^{\circ}$ ); el reconocimiento de la diversidad cultural como fundamento de la nacionalidad y la igualdad y dignidad de todas las culturas que conviven en el país (art. $70^{\circ}$, inc. $2^{\circ}$ ); la obligación del Estado de promover la investigación la ciencia, el desarrollo y la difusión de los valores culturales de la Nación (art. 70, inc. $2^{\circ}$ ); la protección por el Estado del patrimonio cultural de la nación y el reconocimiento de los derechos especiales que pudieran tener los grupos étnicos asentados en territorios de riqueza arqueológica (art. $72^{\circ}$ ). Esto sólo para nombrar algunos de los artículos de la Constitución relacionados con el principio de la diversidad (Colombia. Minsterio de Cultura, 1998 y 1999).
}

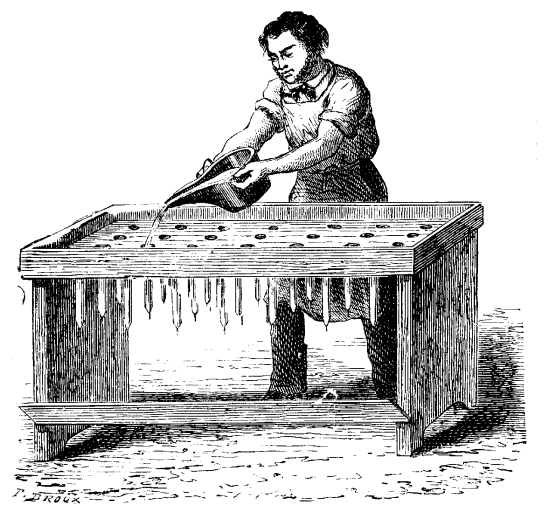

tumbres que cobijaran a todos los ciudadanos. En esta perspectiva la educación tenía una finalidad claramente definida: asegurar una sociedad uniforme, donde los grupos minoritarios, abandonando su cultura, se doblegaran a los dictámenes del grupo o grupos hegemónicos.

A comienzos del tercer milenio el desafío es diferente. El concepto de ciudadanía no se basa sólo en la igualdad, sino también y principalmente en la diferencia. El modelo educativo no puede seguir teniendo como fundamento la verdad absoluta de la ciencia occidental, sino que debe dar cabida a otras maneras de significar la realidad, a otras lógicas y otras racionalidades, es decir, a otras formas distintas de conocimiento. "El reconocimiento de la diversidad étnica y cultural en la Constitución supone la aceptación de la alteridad ligada a la aceptación de multiplicidad de formas de vida y sistemas de comprensión del mundo diferentes de los de la cultura occidental" (Cifuentes, E., Corte Constitucional, 1993, en Ministerio de Cultura, 1998: 7).

Se trata, entonces, de construir un nuevo modelo de educación, que reconozca múltiples identidades y contribuya a su fortalecimiento. "La integración social en las sociedades modernas, complejas, plurales y democráticas no se puede llevar a cabo ya con procesos uniformadores sino a través de la asimilación de la diversidad cultural unida a una política de oportunidades y de derechos ciudadanos" (Picó, 1999: 247).

Pero, al mismo tiempo, se requiere una educación intercultural. Como advierte la UNESCO, el multiculturalismo no se puede reducir a una mera yuxtaposición de culturas, "Se debe avanzar hacia el replanteamiento de un espíritu más profundo de 'interculturalismo' adaptado a un mundo de movimientos, contactos, intercambios y negociaciones que dan lugar a identidades $y$ culturas dinámicas y flexibles, no estáticas y rígidas" (UNESCO, 1998: 7).

Educación, en y para la diversidad, significa, además de promover el fortalecimiento de la identidad étnica y cultural, trabajar en la perspectiva de que cada persona, cada grupo se abra a los demás y en esa interrelación se descubra a sí mismo, siendo consciente de que "La diversidad constituye la historia que nos relata cómo nuestras interacciones con muchas clases de personas nos convierten en lo que somos" (Postman citado en Savater, 2000: 4).

La democracia implica el reconocimiento de las diferencias, por lo cual, una educación en y para la diversidad es también una educación en y para la democracia. 


\section{BIBLIOGRAFÍA}

Abadía Morales, Guillermo. (1977). Compendio General de Folklore Colombiano. Instituto Colombiano de Cultura. Biblioteca Básica Colombiana, Bogotá.

Arango, Raúl y Sánchez, Enrique. (1998). Los pueblos indígenas de Colombia. Tercer Mundo-Departamento Nacional de Planeación, Santa Fe de Bogotá.

ArochA, Jaime. (1999). Ombligados de Ananse. Hilos ancestrales y modernos en el Pacífico colombiano. Facultad de Ciencias Sociales, Universidad Nacional de Colombia. Santa Fe de Bogotá.

Escobar, Arturo, Pedrosa, Álvaro. (1996). Pacífico ¿Desarrollo o diversidad? Ecofondo-Cerec, Santa Fe de Bogotá.

Friedemann, Nina S. (de) y Arocha, Jaime. (1986). De sol a sol. Génesis, transformación y presencia de los negros en Colombia. Planeta.

Gutiérrez de Pineda, Virginia. (1994). Familia y cultura en Colombia. Universidad de Antioquia, Medellín. (Primera edición: Universidad Nacional de Colombia, Bogotá, 1968).

Hederich, M., Christian y Camargo, U., Ángela. (1999). Estilos cognitivos en Colombia. Santa Fe de Bogotá: Universidad Pedagógica $\mathrm{Na}$ cional, Colciencias.

Kymlicka, Will, Norman, Wayne. (1997). Retorno del ciudadano. Una revisión de la producción reciente en teoría de la ciudadanía. La Política. Barcelona, № 3 (octubre): 5-39.

Losonczy, Anne Marie. (1993). "De lo vegetal a lo humano: un modelo cognitivo afrocolombiano del Pacífico" En: Revista Colombiana de Antropología. Vol. XX. Bgootá: Instituto Colombiano de Antropología.

Maya Restrepo, Adriana. (1992). Las brujas de Zaragoza: Resistencia y cimarronaje en las Minas de Antioquia, Colombia 1619-1622. América Negra. Expedición Humana. Bogotá: Pontificia Universidad Javeriana. № 4 (diciembre): 85-98.

(1994). Propuesta de estudio para una formación afroamericanística. América Negra. Expedición Humana. Bogotá: Pontificia Universidad Javeriana, № 7, (junio): 139 158.

(1996). Africa: Legados espirituales en la Nueva Granada, Siglo XVII. Historia Crítica. Santa Fe de Bogotá: Facultad de Humanidades y Ciencias Sociales. Universidad de Los Andes, № 12 (enero-junio): 29-40.

1998a) (Ed.). Los Afrocolombianos. Geografía humana de Colombia. Tomo VI. Santa Fe de Bogotá: Instituto Colombiano de Cultura Hispánica.

1998b). "Brujería y reconstrucción étnica de los esclavos del Nuevo Reino de Granada, Siglo XVII". En: Maya Restrepo, Adriana (Ed.). Los Afrocolombianos. Geografía humana de Colombia. Tomo VI. Santa Fe de Bogotá: Instituto Colombiano de Cultura Hispánica. 193217.

MINISTERIO DE CULTURA. DIRECCIÓN DE ETNOCULTURA. (1998). Opción Común. Colombia multiétnica y pluricultural. Santa Fe de Bogotá. Inédito.
(1999). Diálogos de Nación en la Colombia Multiétnica y Pluricultural. Santa Fe de Bogotá. Inédito.

Monsalve Solórzano, Alfonso. (1997). El Multiculturalismo en Colombia. Ponencia II Seminario Internacional de Filosofía Política. Instituto de Filosofía, Universidad de Antioquia, Medellín,. Memorias (copia en medio magnético).

Othon de Mendiazabal, Miguel. (1992). Etnicidad y Estructura Social. México: Centro de Investigación y Estudios Superiores en Antropología Social.

PIco, Josep. (1999). Cultura y modernidad. Seducciones y desengaños de la cultura moderna. Madrid: Alianza Editorial.

Savater, Fernando. (2000). "La educación desconcertada". En: Lecturas Dominicales. El Tiempo. Santa Fe de Bogotá, 21 de mayo: 3 - 4.

Trillos Amalla, María (comp.). (1998a). Memorias. Educación endógena frente a educación formal. Santa Fe de Bogotá: Universidad de los Andes.

(1998b). "La Educación Indígena en Colombia. Síntesis del estado del arte presentado en la Antigua Guatemala". En: TriLlos Amalla, María (comp.). Memorias. Educación endógena frente a educación formal. (1998b). Santa Fe de Bogotá: Universidad de los Andes. 69-96.

UNESCO. (1998). Conferencia Intergubernamental sobre Políticas Culturales para el Desarrollo. Documento de Base. Estocolmo, Suecia. 